REVISTA X, Curitiba, volume 13,n.1, p. 116-140, 2018.

Dossiê Especial: Português como Língua Adicional em contextos de minorias:

(co)construindo sentidos a partir das margens

BIZON \& DINIZ (Orgs.)

\title{
"PELO MUNDO": A CONFIGURAÇÃO DE UMA POLÍTICA LINGUÍSTICA NO ENSINO DE PORTUGUÊS COMO LÍNGUA ADICIONAL EM UM CURSO PARA CANDIDATOS AO PROGRAMA DE ESTUDANTES-CONVÊNIO DE GRADUAÇÃO (PEC-G) ${ }^{1}$
}

\begin{abstract}
"Around the World": The Configuration of Aa Language Policy in ihe Teaching Of Portuguese as an Additional Language in a Course For Candidates For The Exchange Program For Undergraduate Students (PEC-G)
\end{abstract}

Yara Carolina Campos de MIRANDA, $\mathrm{UFMG}^{2}$

\begin{abstract}
RESUMO: Neste artigo, tenho como foco o funcionamento do Programa de Estudantes-Convênio de Graduação (PEC-G) que, como destacado no site do Ministério das Relações Exteriores (MRE) ${ }^{3}$, permite que estudantes estrangeiros vindos de países em desenvolvimento com os quais o governo brasileiro mantém acordos educacionais e culturais possam realizar estudos de graduação no Brasil. Uma das exigências para participação nesse programa é a apresentação do Certificado de Proficiência em Língua Portuguesa para Estrangeiros (Celpe-Bras). Candidatos de países onde não há aplicação do exame podem realizá-lo no Brasil após terem concluído curso de português como língua adicional (PLA) em IES credenciadas. Em um desses cursos, sediado em uma universidade federal brasileira, desenvolveu-se o "Projeto Pelo Mundo", em 2015. Alicerçado na perspectiva da Linguística Aplicada Indisciplinar (MOITA LOPES, 2006) e do Letramento Crítico (LUKE, 2003; MATTOS; VALERIO, 2010; JORDÃO, 2014), tal projeto procurou contribuir para a formação de uma consciência crítica e cidadã dos estudantes em relação à forma como se posicionavam e eram posicionados pelos Outros (BIZON, 2013) na sociedade à qual buscavam se integrar. Neste trabalho, analiso algumas das contribuições desse projeto para a configuração de uma política linguística pluricêntrica que coopere para a visibilização do PEC-G no processo de internacionalização das IES brasileiras, assim como para uma formação crítica dos estudantes e para a educação do entorno (MAHER, 2007).
\end{abstract}

PALAVRAS-CHAVE: Programa de Estudantes-Convênio de Graduação (PEC-G); Português Língua Adicional (PLA); Políticas Linguísticas; Educação do Entorno.

ABSTRACT: In this article, I focus on the functioning of the Exchange Program for Undergraduate Students (PEC-G), which, as highlighted on the Ministry of Foreign

\footnotetext{
${ }^{1}$ Este artigo é resultado de minha pesquisa de mestrado, desenvolvida entre os anos de 2015 e 2016 no Programa de Pós-Graduação em Estudos Linguísticos da Faculdade de Letras da Universidade Federal de Minas Gerais, com auxílio da bolsa de estudos da CAPES, à qual registro meu agradecimento.

2 Doutoranda em Estudos Linguísticos pelo Programa de Pós-Graduação em Estudos Linguísticos da Universidade Federal de Minas Gerais (PosLin/UFMG). Email: yaracarolina2@gmail.com

${ }^{3}$ Disponível em:< http://www.dce.mre.gov.br/PEC/PECG.php >. Acesso em 13 mar. 2018.
} 
REVISTA X, Curitiba, volume 13,n.1,p. 116-140, 2018.

Dossiê Especial: Português como Língua Adicional em contextos de minorias:

(co)construindo sentidos a partir das margens

BIZON \& DINIZ (Orgs.)

Affairs (MRE) site, allows foreign students from developing countries with whom the Brazilian government maintains educational and cultural agreements, to undertake undergraduate studies in Brazil. One of the requirements for this program is for participants to present the Certificate of Proficiency in Portuguese for Foreigners (Celpe-Bras). Candidates from countries where the exam is not administered may take the test in Brazil, after having completed a Portuguese as an Additional Language (PLA) course at an accredited institution of higher education. In one of these courses based in a Brazilian federal university, the "Around the world" project was developed in 2015. Based on the perspective of the Interdisciplinary Applied Linguistics (MOITA LOPES, 2006) and Critical Literacy (LUKE, 2003; MATTOS; VALERIO, 2010; JORDÃO, 2014), this project aimed at contributing to the development of a critical civic consciousness on the part of the students, concerning the ways in which they positioned themselves and were positioned by Others (BIZON, 2013) in the society to which they sought to integrate. In this paper, I analyse some contributions of this project for the configuration of a pluricentric linguistic policy that cooperates to the visibility of PEC-G in the internationalization process of the Brazilian higher education institutions, as well as to a critical education of students and to the education of the surroundings (MAHER, 2007).

Keywords: Exchange Program for Undergraduate Students (PEC-G), Portuguese as an Additional Language (PLA), Language Policy, Education of the Surroundings.

\section{INTRODUÇÃO}

O Programa de Estudantes-Convênio de Graduação (doravante PEC-G) teve origem no final da década de 1920, sendo operacionalizado somente em 1965, por meio de um protocolo que estabelece um "tratado de cooperação educacional do governo brasileiro com países em desenvolvimento com os quais o Brasil mantém acordo de cooperação cultural e/ou educacional e/ou de ciência e tecnologia, objetivando a formação de recursos humanos"4.

Desenvolvido pelo Ministério das Relações Exteriores (MRE) em parceria com Instituições de Ensino Superior (IES) públicas (federais e estaduais) e particulares, o PEC-G dá a estrangeiros que tenham completado o Ensino Médio a "oportunidade" 5 de

\footnotetext{
${ }^{4}$ Disponível em <http://www.dce.mre.gov.br/ >. Acesso em 20 nov. 2015.

${ }^{5}$ Utilizamos aspas aqui para desnaturalizar os efeitos de sentido produzidos por alguns termos utilizados no discurso oficial referente ao programa, que tendem a criar um imaginário de fraternidade na relação entre o Brasil e países conveniados ao PEG-G, silenciando interesses estratégicos daquele país em relação a estes, como destacam Diniz e Bizon (2015).
} 
REVISTA X, Curitiba, volume 13,n.1,p.116-140, 2018.

Dossiê Especial: Português como Língua Adicional em contextos de minorias:

(co)construindo sentidos a partir das margens

BIZON \& DINIZ (Orgs.)

realizar seus estudos de graduação no Brasil, como é possível constatar no site da Divisão de Temas Educacionais do Itamaraty ${ }^{6}$. Como salienta Franco (2015), o PEC-G surge em um período em que o Brasil almejava fortalecer suas relações com os países africanos.

Minha primeira experiência como professora de português como língua adicional (PLA) para candidatos ao PEC-G se deu em 2008, contudo, somente em minha segunda experiência com esse público, em 2013, conheci realmente o programa e suas especificidades. Como pude constatar em minha jornada como professora de PLA para estudantes do Curso de PLA para Candidatos ao PEC-G, mesmo tendo mais de 50 anos de existência, esse convênio é ainda pouco visibilizado no contexto universitário brasileiro. Durante o desenvolvimento de minha pesquisa, tive a oportunidade de tratar do programa em diferentes eventos acadêmicos e, em quase todos, pude observar, um tanto perplexa, o fato de que a maioria dos graduandos, pesquisadores e professores de universidades conveniadas ao PEC-G desconhece sua existência.

Se o convênio tem pouca visibilidade mesmo em contextos em que há um número expressivo de estudantes a ele vinculados, ainda mais invisíveis se tornam questões fundamentais sobre o funcionamento do PEC-G, cujas discussões se fazem necessárias para o bom desempenho das alunas e alunos que chegam ao Brasil para cursar a graduação nas IES brasileiras credenciadas.

Em vista disso, o presente artigo, amparado pelas discussões propostas pela Linguística Aplicada Indisciplinar (MOITA LOPES, 2006) e do Letramento Crítico (LC) (LUKE, 2003; MATTOS; VALERIO, 2010; JORDÃO, 2014), visa a analisar o projeto "Pelo Mundo" (PPM), desenvolvido no âmbito do Curso de PLA para Candidatos ao PEC-G oferecido por uma universidade federal brasileira, no ano de 2015. Com o apoio de cinco professoras e do coordenador do curso, os estudantes desenvolveram uma série de atividades e ações, por meio das quais puderam aprender o português, preparar-se para o exame Celpe-Bras - cuja certificação é uma das exigências para que esses estudantes possam, de fato, participar do convênio - e para a

\footnotetext{
${ }^{6}$ Idem.
} 
REVISTA X, Curitiba, volume 13,n.1,p.116-140, 2018.

Dossiê Especial: Português como Língua Adicional em contextos de minorias:

(co)construindo sentidos a partir das margens

BIZON \& DINIZ (Orgs.)

entrada na universidade, enquanto, concomitantemente, refletiam criticamente ${ }^{7}$ sobre suas próprias construções culturais, na interface com construções culturais de seus mais diferentes interlocutores no Brasil. Tais práticas proporcionaram, assim, reflexões potenciais para o questionamento de alguns estereótipos comuns formados a respeito de suas culturas no meio acadêmico e na sociedade em que estavam inseridos, que, de alguma forma, os inquietavam, como demonstraram em diversos relatos em sala de aula e em conversas com as professoras.

É nesse contexto que se dá a presente pesquisa, cujo foco é analisar algumas das contribuições do PPM para a configuração de uma política linguística pluricêntrica capaz de favorecer a visibilização do PEC-G no processo de internacionalização das IES brasileiras, assim como para uma formação crítica dos estudantes e para a educação do entorno $^{8}$ (MAHER, 2007).

\section{CONTEXTO DE PESQUISA}

O PEC-G é regido pelo decreto da presidenta Dilma Rousseff de $\mathrm{N}^{\circ} 7.948$, de 12 de março de 2013. Foi criado, também, o Manual do Estudante-Convênio (BRASIL, 2000), o qual pode ser encontrado no site do DCE/MRE. Ambos os documentos discorrem sobre questões referentes ao processo para a participação no programa, assim como regulamentos dos quais tanto os estudantes como os responsáveis pelo programa nas IES devem estar cientes. Alguns dos deveres dos estudantes-convênio participantes do PEC-G, mencionados no Manual do Estudante-Convênio (BRASIL, 2000), são: contar com recursos financeiros suficientes para custear sua manutenção no Brasil (moradia, alimentação, transporte, vestuário, material didático etc.); dedicar-se exclusivamente aos estudos; não exercer atividade remunerada que configure vínculo

\footnotetext{
${ }^{7}$ Monte Mór (2013) discute o termo crítica ou crítico em debates sobre educação na atualidade. Como aponta a autora, a partir de Gikandi (2005), é possível distinguir dois diferentes sentidos em inglês criticism e critique - para o que, em português, se traduz por crítica. Neste estudo, quando refletimos sobre um processo de ensino-aprendizagem crítico, ou uma educação crítica, compreendemos crítico/crítica a partir da definição de critique, considerando que essa crítica "remete a uma vivência social, a uma reorganização do conhecimento e a uma autoria nos sentidos construídos pelo leitor, espectador, interlocutor, pessoa, enfim, cidadão" (Ibidem, p. 43).

${ }^{8}$ Este conceito será discutido na seção sobre referencial teórico-metodológico.
} 
REVISTA X, Curitiba, volume 13,n.1,p. 116-140, 2018.

Dossiê Especial: Português como Língua Adicional em contextos de minorias:

(co)construindo sentidos a partir das margens

BIZON \& DINIZ (Orgs.)

empregatício ou que caracterize pagamento de salário ou honorários por serviços prestados.

Tais exigências causam, inúmeras vezes, bastantes dificuldades para os conveniados do PEC-G. Como salienta Bizon (2013), aqueles que vêm ao Brasil para aprender o português e prestar o Celpe-Bras um ano antes de ingressarem nos cursos de graduação não têm, à sua disposição, mecanismos de ajuda financeira providos pelo MRE durante esse período. É preciso destacar que, se por um lado, o programa recebe alguns estudantes das elites de seus países cujas famílias têm condições para custear suas despesas no Brasil, por outro, também vêm pelo programa estudantes de condições financeiras adversas, que apresentam bastante dificuldade para se manterem no país anfitrião ${ }^{9}$. Eles contam com o apoio financeiro, na maioria das vezes, de suas famílias, que enviam dinheiro para custear despesas com alimentação, moradia, transporte, material didático etc. Presume-se que, tendo apresentado documento comprobatório de renda familiar capaz de sustentá-los enquanto afiliados ao PEC-G, os estudantes tenham capacidade de arcar com os custos de vida no Brasil. Todavia, em alguns casos, pelas situações com que nos deparamos como professoras desses alunos, observamos que há falha, como também aponta Bizon (2013), na regulamentação desse documento.

$\mathrm{Na}$ instituição de ensino superior onde se desenvolveu esta pesquisa, também foi possível observar, na trajetória dos estudantes com os quais convivi, as consequências dessas questões tão complexas aqui mencionadas. Fui professora de português no Curso de PLA para Candidatos ao PEC-G nos anos de 2008, 2013, 2014, 2015, 2016 e 2017. Durante esse tempo, pude conhecer estudantes de diferentes nacionalidades, de diferentes origens, com diferentes objetivos e motivos que os trouxeram ao Brasil por meio do PEC-G. E não foram poucas as vezes em que, como professora deles durante longos períodos de tempo - em geral, os cursos duravam cerca de oito meses, com carga horária média de 20 horas semanais de aulas, ministradas por cinco ou seis professoras diferentes -, participei de suas angústias, inquietações e dificuldades.

\footnotetext{
${ }^{9}$ Cabe lembrar que tais estudantes não têm o direito de exercer atividade remunerada que os ajude a se sustentarem de forma independente.
} 
REVISTA X, Curitiba, volume 13,n.1,p. 116-140, 2018.

Dossiê Especial: Português como Língua Adicional em contextos de minorias:

(co)construindo sentidos a partir das margens

BIZON \& DINIZ (Orgs.)

Essas, apenas algumas das intricadas questões que envolvem a vida de muitos estudantes do PEC-G no Brasil, podem causar diversas situações bastante complexas, tanto para os alunos como para seus professores e professoras, assim como para as IES. Alguns dos alunos e das alunas acabam vivendo em condições complicadas enquanto tentam administrar sua vida financeira e a dificuldade já inerente de adaptação para qualquer estudante que ingressa em uma faculdade. Torna-se um cenário ainda mais desafiador para aquele que ainda está aprendendo a língua e se adaptando às construções culturais em que está se inserindo.

Além das situações já apresentadas, é necessário ressaltar a exigência do CelpeBras para participação no programa, que tem grandes impactos no modo como o Curso de PLA para Candidatos ao PEC-G se constitui e nos materiais utilizados em aula, assim como nas práticas de ensino-aprendizagem e avaliação desenvolvidas pelos professores e estudantes. A obrigatoriedade do exame gera bastante ansiedade, tanto para estudantes, quanto para as professoras envolvidas no curso. Em um texto produzido em sala de aula na edição do curso de 2016, uma estudante camaronesa escreveu: "Conseguir o Celpe-Bras é a chave de nosso futuro, uma grande oportunidade para nós de realizar nossos sonhos". Observamos que o Celpe-Bras é significado não como uma, mas como " $a$ chave para o futuro". Sem essa certificação, ela não terá a possibilidade de realizar sua graduação no Brasil pelo programa para o qual está se candidatando, o que implicaria, segundo o que ela escreve, não realizar seus sonhos.

Todos esses aspectos perpassavam o Curso de PLA para Candidatos ao PEC-G focalizado neste estudo. $\mathrm{O}$ ano de 2015 era o terceiro consecutivo em que eu trabalhava nesse contexto, sob a coordenação de um professor efetivo da universidade federal anfitriã. Naquele ano, os alunos tiveram quatro horas de aula no curso de PLA, de segunda a sexta-feira, de fevereiro a outubro (quando é aplicada a segunda edição do Celpe-Bras) e cada professora era responsável pelas aulas de um dos dias da semana ${ }^{10}$. Em reuniões pedagógicas, definíamos os conteúdos que seriam ministrados nos próximos quinze dias do curso, e planejávamos as unidades didáticas a serem

\footnotetext{
${ }^{10}$ Excepcionalmente naquele ano, o curso contou com a participação de seis professoras. Duas delas alternavam sua participação nas aulas de sexta-feira.
} 
REVISTA X, Curitiba, volume 13,n.1,p. 116-140, 2018.

Dossiê Especial: Português como Língua Adicional em contextos de minorias:

(co)construindo sentidos a partir das margens

BIZON \& DINIZ (Orgs.)

elaboradas, todas pelas próprias professoras, considerando que optamos por não adotar nenhum livro didático. Para isso, trabalhávamos com a perspectiva do LC (LUKE, 2003; MATTOS; VALERIO, 2010; JORDÃO, 2014), considerando suas muitas contribuições para o ensino de línguas adicionais. Conhecer e trabalhar com a concepção do LC modificou também meu posicionamento diante de alguns acontecimentos em sala de aula, como veremos posteriormente. Em nossas propostas de atividades, buscávamos trabalhar com uma ampla diversidade de gêneros discursivos, tanto para práticas de compreensão quanto de produção oral e escrita.

Como resultado desse trabalho colaborativo entre as professoras e os estudantes, esses começaram a trazer para as discussões em sala de aula algumas de suas inquietações quanto ao modo como eram narrados pela comunidade ao seu redor, inclusive pelos próprios colegas de sala originários de dez diferentes nacionalidades. Em uma de minhas aulas, alguns estudantes de países africanos (sobretudo um estudante do Gabão, outro do Togo e um da Namíbia) se ofenderam com uma questão feita por uma colega da Guatemala. Ela perguntou se era verdade que não havia água em algumas partes da África e que algumas pessoas, por isso, precisavam beber urina para não morrer por desidratação. Ainda que ela tentasse explicar que havia visto aquilo em uma postagem sobre ajuda humanitária em uma rede social, alguns de seus colegas, bastante ofendidos, levantaram um grande embate em nossa sala.

Em meio a toda aquela discussão, já engajada com estudos sobre o LC e a Linguística Aplicada Indisciplinar, vislumbrei uma excelente oportunidade para problematizar a situação. Utilizando-me de ferramentas como Google Images e materiais que eu tinha em meu computador, comecei a fazer algumas perguntas aos estudantes para que, juntos, observássemos de que formas nossos países - tanto os países deles quanto o Brasil - eram representados pela grande mídia. Depois de discutirmos bastante de forma muito interativa - já que todos pareciam pessoalmente envolvidos naquele tema -, propus que se juntassem em pequenos grupos e pensassem em iniciativas que pudessem contribuir para mostrar à sociedade na qual se inseriam inclusive, aos colegas de sala - outras faces de seus países, diferentes daquelas apresentadas pela grande mídia, que pareciam incomodá-los e, até mesmo ofendê-los. 
REVISTA X, Curitiba, volume 13,n.1,p.116-140, 2018.

Dossiê Especial: Português como Língua Adicional em contextos de minorias:

(co)construindo sentidos a partir das margens

BIZON \& DINIZ (Orgs.)

Reunindo algumas das ideias apresentadas pelos estudantes, elaboramos o PPM, que apresentarei mais profundamente na seção de registros de dados deste artigo.

\title{
REFERENCIAL TEÓRICO-METODOLÓGICO
}

Nesta seção, trato do referencial teórico e apresento a metodologia utilizada para este trabalho. Apresento, brevemente, as perspectivas da Linguística Aplicada Indisciplinar, do LC e os conceitos de política linguística e educação do entorno.

Em seu trabalho publicado em $2006^{11}$, Moita Lopes cunha o termo Linguística Aplicada Indisciplinar, defendendo que a LA não é uma simples aplicação da linguística. A concepção desse autor sobre essa área circunscreve-se na perspectiva da Linguística Aplicada Crítica, que, segundo Pennycook (2006, p. 67), constitui-se como "uma abordagem mutável e dinâmica para as questões da linguagem em contextos múltiplos”. Em concordância com Pennycook (ibidem), Moita Lopes (2006) concebe a LA Indisciplinar como uma Linguística Aplicada que

\begin{abstract}
não tenta encaminhar soluções ou resolver os problemas com que se defronta ou constrói. Ao contrário, a LA procura problematizá-los ou criar inteligibilidade sobre eles, de modo que alternativas para tais contextos de usos da linguagem possam ser vislumbradas (MOITA LOPES, 2006, p. 20).
\end{abstract}

Nesse sentido, Moita Lopes (2006) ressalta a necessidade de se "repensarem outros modos de teorizar e fazer LA" (ibidem, p. 21). Analisando os pressupostos da Linguística Aplicada Indisciplinar, é possível notar sua consonância com a perspectiva poscolonialista. Para Cavalcanti (2013), essa visão se mostra mais condizente com o mundo contemporâneo, apesar de não estar tão presente na filosofia de currículos que embasam a formação de professores. Um contexto em constante movimento de mudanças chama a Linguística Aplicada a se repensar, a refletir sobre si mesma, enquanto busca colaborar na "construção de uma agenda anti-hegemônica em um

\footnotetext{
${ }^{11}$ MOITA LOPES, L. P. Por uma Linguística Aplicada Indisciplinar. São Paulo: Parábola Ed., 2006.
} 
REVISTA X, Curitiba, volume 13,n.1,p. 116-140, 2018.

Dossiê Especial: Português como Língua Adicional em contextos de minorias:

(co)construindo sentidos a partir das margens

BIZON \& DINIZ (Orgs.)

mundo globalizado, ao mesmo tempo em que descreve a vida social e as formas de conhecê-la" (MOITA LOPES, 2006, p. 27). Isto posto, conclui-se que a Linguística Aplicada Indisciplinar pode ser inscrita no bojo do que Moita Lopes (2006) chama de uma Linguística Aplicada mestiça, de natureza interdisciplinar ou transdisciplinar, em um movimento de pesquisadores que buscam "criar inteligibilidade sobre problemas sociais em que a linguagem tem um papel central" (ibidem, p.14).

Também o LC emerge da abordagem da Linguística Aplicada Crítica. Como destacam Mattos e Valério (2010), os estudos do LC se debruçam sobre o caráter ideológico da comunicação e têm como objetivo principal o desenvolvimento da consciência crítica. Assim, essa perspectiva "pretende mudar a sociedade, promovendo a inclusão social de grupos marginalizados" (ALFORD, 2001 apud MATTOS; VALÉRIO, 2010) à medida que expande o escopo de identidades sociais de forma que haja possibilidade de transformação (JORDÃO, 2007).

Conforme discute Jordão (2014), o LC apresenta um diferente olhar sobre as práticas do letramento em relação a abordagens anteriores, como a abordagem comunicativa e a pedagogia crítica. Segundo ela, "nessa nova visão, realidade e observador são inseparáveis: só se tem conhecimento do real mediante nosso olhar, nossa leitura dele" (ibidem, p. 198). A autora atenta para o fato de que "ao ver, já estamos imprimindo interpretações para aquilo que vemos - só podemos ver justamente porque interpretamos, ao ver já estamos conferindo sentido ao que vemos" (loc. cit.). Jordão (2014) conclui que, sob a perspectiva da LC, o papel do professor consiste em ampliar as possibilidades de "procedimentos interpretativos e visões de mundo para poder ajudar os alunos a ampliarem também os seus” (JORDÃO, ibidem, p. 201). Assim, alunos e professores têm papel agentivo na criação de sentidos diante das práticas de letramentos às quais se expõem. Dessa forma, enquanto se perguntam sobre seu próprio fazer interpretativo, veem-se, criticamente, tanto como narradores quanto narrados (ibidem), e, ao perceberem-se assim, podem se "posicionar como participantes ativos da sociedade, capazes de recontar e refazer sua história" (ibidem, p. 202). Como sublinha Jordão (ibidem), no LC, não é somente o professor que traz para a sala de aula conhecimentos legítimos, mas, no ato educativo, também os estudantes são personagens 
REVISTA X, Curitiba, volume 13,n.1,p.116-140, 2018.

Dossiê Especial: Português como Língua Adicional em contextos de minorias:

(co)construindo sentidos a partir das margens

BIZON \& DINIZ (Orgs.)

principais na construção de saberes legítimos. A partir de Freire (1998) e Ferraz (2014), a autora insiste no reconhecimento de que os alunos "sabem coisas e essas coisas são importantes, precisam ser valorizadas e valem a pena ser compartilhadas" (ibidem, p. 202, grifos da autora).

Fica evidente, portanto, que o LC está em consonância com os pressupostos da Linguística Aplicada Indisciplinar, pois percebe a heterogeneidade dos sujeitos (MOITA LOPES, 2006) e atenta para a necessidade de uma contínua reflexão sobre as práticas em que pesquisadores, professores e estudantes se envolvem nos processos de ensino-aprendizagem de línguas e nas pesquisas que buscam contribuir para essas práticas.

Antes de finalizar esta seção, faz-se necessário abordar outros dois conceitos caros a esta pesquisa, a saber: políticas linguísticas e educação do entorno. Na perspectiva deste trabalho, políticas linguísticas não compreendem apenas "a determinação das grandes decisões referentes às relações entre as línguas e a sociedade" (CALVET, 2007, p. 11, apud DINIZ, 2012, p. 15). Entendo que políticas linguísticas devem incluir atos públicos, documentos oficiais, mas, além disso, deve-se considerar a forma como estas constituem e são constituídas pelas práticas sociais em que nos engajamos cotidianamente (McCARTY, 2004; MAHER, 2008; DINIZ, 2012; BIZON, 2013). Assim, a escolha dos materiais utilizados em sala de aula e da forma como os professores medeiam as discussões em uma atividade didática são igualmente constituídas por políticas linguísticas e as constituem. Professores e professoras, alunos e alunas, coordenadoras e coordenadores também participam da constituição e implementação dessas políticas linguísticas.

Sobre o conceito de educação do entorno, Maher (2007) salienta que o empoderamento de grupos minoritarizados ${ }^{12}$ "não depende apenas de seu fortalecimento político ou da existência de legislações a eles favoráveis, mas também da educação do

\footnotetext{
${ }^{12}$ Considero os estudantes do PEC-G como membros de um grupo potencialmente minoritarizado devido às condições de vulnerabilidade que, muitas vezes, vivenciam, e devido ao seu frequente apagamento pelos órgãos responsáveis pelo programa e pela comunidade acadêmica, como é possível constatar em pesquisas como as de Bizon (2013), Diniz e Bizon (2015) e Miranda (2016).
} 
REVISTA X, Curitiba, volume 13,n.1,p. 116-140, 2018.

Dossiê Especial: Português como Língua Adicional em contextos de minorias:

(co)construindo sentidos a partir das margens

BIZON \& DINIZ (Orgs.)

seu entorno para garantir esse respeito". Para a autora, não basta que as minorias ${ }^{13}$ sejam conscientes de seus direitos para alcançá-los. O empoderamento de grupos minoritários decorre do que denomina de três "cursos de ação": "(1) sua politização; (2) o estabelecimento de legislações a eles favoráveis; e (3) a educação do seu entorno para o respeito à diferença" (ibidem, p. 257). Portanto, como conclui,

[...] A politização é apenas um dos alicerces - um alicerce absolutamente necessário, mas não suficiente [...] Sem que o entorno aprenda a respeitar e a conviver com diferentes manifestações linguísticas e culturais, mesmo que fortalecidos politicamente e amparados legalmente, [...] os grupos que estão à margem do mainstream não conseguirão exercer, de forma plena, sua cidadania (ibidem, p. 257-258).

Os apontamentos apresentados nesta seção nos auxiliarão a analisar o PPM e seus possíveis efeitos para contribuir com a educação do entorno para a diferença linguística e cultural no âmbito em que se desenvolveu.

Finalmente, destaco que este trabalho resulta de minha pesquisa de mestrado, realizada em 2016, cujo objetivo foi analisar a política linguística que se configurou no desenvolvimento do PPM no âmbito do Curso de PLA para Candidatos ao PEC-G. Para minhas análises, utilizei meu próprio diário reflexivo, que foi produzido durante os anos de 2015 e 2016. Nele, escrevia acontecimentos que considerava interessantes ou intrigantes em minha prática em sala de aula com os estudantes do mencionado curso. Também realizei entrevistas com duas professoras que trabalharam naquele contexto à época (Sè e Amie ${ }^{14}$ ); duas professoras da Faculdade de Letras da IES onde se deu o PPM, as quais assistiram a algumas das apresentações artísticas que constituíram o projeto aqui focalizado (Marie e Luz); cinco estudantes do PEC-G que participaram do PPM à época de seu desenvolvimento e, por fim, Marcius, monitor de uma escola municipal de Belo Horizonte que convidou os estudantes do Curso de PLA para Candidatos ao PEC-G para participarem de uma atividade sobre africanidade na escola em que atuava.

\footnotetext{
${ }^{13}$ A autora esclarece que o termo "minorias" não está sendo utilizado, necessariamente, em um sentido demográfico (MAHER, 2007, p. 257).

${ }^{14}$ Os nomes utilizados para designar os participantes da pesquisa são fictícios, a fim de preservar seu anonimato por questões de ética de pesquisa.
} 
REVISTA X, Curitiba, volume 13,n.1,p.116-140, 2018.

Dossiê Especial: Português como Língua Adicional em contextos de minorias:

(co)construindo sentidos a partir das margens

BIZON \& DINIZ (Orgs.)

$\mathrm{Na}$ próxima seção, apresento alguns dos registros gerados no decorrer da pesquisa e sua análise.

\section{REGISTROS E ANÁLISES}

Nesta seção, apresento alguns recortes das análises de registros realizadas em minha pesquisa de mestrado. Minha seleção se fez no intuito de apresentar aquelas que considero algumas das principais contribuições do PPM para a configuração de uma política linguística pluricêntrica ${ }^{15}$ que possa cooperar para a visibilização do PEC-G no processo de internacionalização das IES brasileiras, assim como para uma formação crítica dos estudantes e para a educação do entorno (MAHER, 2007). Para melhor organização das análises, separo-as nos tópicos seguintes.

\section{O projeto Pelo Mundo por meio das vozes de professoras e professores envolvidos}

Foram quatro professoras e um professor entrevistados para esta pesquisa. Para o que pretendo apresentar neste trabalho, porém, seleciono apenas alguns trechos dessas entrevistas, assim como de meu diário reflexivo. Nesta subseção, analiso as contribuições do PPM na perspectiva das professoras entrevistadas.

Em um primeiro momento, preciso mencionar, ainda que brevemente, algumas das atividades desenvolvidas no interior do PPM. Depois da discussão que tivemos em sala, advinda da pergunta da estudante da Guatemala a alguns dos estudantes de países do continente africano, como já mencionei, elaboramos um projeto com iniciativas que os estudantes e as professoras consideraram que poderiam contribuir para promover um maior conhecimento de seus países de origem, construções culturais e inquietações como estudantes internacionais dentro de uma universidade brasileira. Como parte do projeto, os estudantes escreveram, com a ajuda das professoras, uma peça de teatro que trazia, de forma bem-humorada e com bastante ironia, reflexões sobre os diferentes

\footnotetext{
${ }^{15}$ Neste trabalho, considero pluricêntrica aquela política linguística que amplia seu escopo para outras possibilidades que vão para além de uma agenda hegemônica, por exemplo, na contramão de uma política que valoriza unicamente as línguas com maior prestígio no cenário científico internacional.
} 
REVISTA X, Curitiba, volume 13,n.1,p.116-140, 2018.

Dossiê Especial: Português como Língua Adicional em contextos de minorias:

(co)construindo sentidos a partir das margens

BIZON \& DINIZ (Orgs.)

tipos de estereótipos aos quais sempre tinham que responder em sua vida no Brasil. Alguns deles relataram manifestações que consideraram racismo ou xenofobia, e que haviam sido trazidas para discussão em sala de aula pela perspectiva do LC.

Depois de apresentarem a peça teatral em um festival de culturas promovido pela Faculdade de Letras da universidade anfitriã do curso, os estudantes foram convidados, por uma professora adjunta daquela mesma faculdade, para reapresentá-la em um evento acadêmico. Já nessa segunda apresentação, realizada no hall de um dos auditórios da faculdade, a peça de teatro foi vista por outros estudantes da Faculdade de Letras, entre eles, o professor Marcius que, ao final da apresentação, procurou-nos para pedir que os estudantes visitassem a escola municipal na qual trabalhava. Algumas semanas depois, os estudantes do Curso de PLA para Candidatos ao PEC-G foram à escola onde trabalhava o professor Marcius e apresentaram a peça novamente, além de receberem homenagens de agradecimento dos estudantes, que estavam se preparando para um evento sobre negritude e africanidade para o final do ano. Além das apresentações, os estudantes do PEC-G responderam a perguntas dos estudantes daquela escola, falaram sobre suas percepções da vida no Brasil e interagiram com professores e alunos brasileiros.

Isto posto, começo apresentando algumas reflexões trazidas pela entrevista à Marie, professora adjunta da Faculdade de Letras onde se desenvolveu o PPM. Iniciamos com um recorte da entrevista feita com essa professora.

\section{Recorte 1 - Trechos da entrevista com a professora Marie}

PP: E aí... você acredita que projetos como esse têm algum impacto na comunidade acadêmica?

P Marie: Não sei se eu acredito, mas eu gostaria que tivesse, né?! Porque eu faço, às vezes... pelo menos, fazia muito esse tipo de coisas, né? Então, por exe... que não são nada acadêmicas, né? Fazer um teatrinho, né? Montar um coral, né? Coisas desse tipo. Já fiz muito, né? Não só aqui, mas em outras universidades. Sempre gostei disso, né? Mas... cê fica assim pensando... tem que ter esse lado, né? Mas, assim... não é muito valorizado pra você, dentro, né?... vamos dizer assim, dentro do seu relatório anual. [...] Então tem gente que nem pensa nisso, né? Porque "ah, não vai contar nada pro [entrevistada faz referência ao relatório anual das atividades docentes, exigido em sua instituição]", né? Mas é a coisa que eu mais tenho prazer, exatamente o que não é muito acadêmico, né? Então, eu gostaria que tivesse um impacto, né?

(MIRANDA, 2016, p. 103-104) 
REVISTA X, Curitiba, volume 13,n.1,p. 116-140, 2018.

Dossiê Especial: Português como Língua Adicional em contextos de minorias:

(co)construindo sentidos a partir das margens

BIZON \& DINIZ (Orgs.)

Nesse recorte, observamos uma visão um tanto desacreditada de Marie quanto ao impacto de atividades como o PPM dentro da universidade. Como é possível notar em seu discurso, não se trata de uma descrença da professora quanto à importância de projetos como este, mas, sim, em seu receio de que esse tipo de iniciativa não seja considerado "dentro do seu relatório anual", que seriam suas obrigações para com a universidade devido ao cargo que ela exerce na instituição. Note-se a mudança do presente do indicativo para o pretérito perfeito do indicativo em "...eu faço, às vezes... pelo menos, fazia muito esse tipo de coisas, né?”, que demonstra uma mudança em sua prática docente na trajetória como professora desde o passado até o presente, provavelmente motivada pela não inclusão de iniciativas como o PPM, já naturalizadas para a professora como "nada acadêmicas", em seu relatório anual institucional. Também o uso do diminutivo em "teatrinho" pode ser uma marca em seu discurso do valor atribuído a esse tipo de atividade no âmbito acadêmico como algo menor, pouco valorizado dentro das atividades que devem ser desempenhadas pelos professores universitários.

Essa questão já foi abordada em outros trabalhos, como o de Bizon (2013). Ao abordar o tema dos processos de internacionalização das IES brasileiras, a autora chama a atenção para o "capitalismo acadêmico" (SLAUGHTER; LESLIE, 2001). Como explica Bizon (ibidem), esse novo modo de fazer a universidade em tempos de globalização intensificada caracteriza-se pelo deslocamento de uma política voltada para "indagações e curiosidades científicas" (BIZON, 2013, p. 43) para uma preocupação com "interesses comerciais e estratégicos" (loc. cit.). Nas palavras de Krawczyk (2008),

Nesta fase de capitalismo acadêmico, os pesquisadores e administradores universitários são induzidos a participar de ambientes competitivos para captação de recursos públicos e privados, direcionando seus projetos segundo os interesses do mercado. A tendência ao "capitalismo acadêmico" produz "acadêmicos" que cultivam perspectivas e comportamentos institucionais semelhantes ao empreendedor no mercado, usando sua lógica para competir por verbas externas para pesquisa, investimentos institucionais, parcerias empresa-universidade e outras formas de geração de recursos financeiros (KRAWCZYK, 2008, p. 43, apud BIZON, 2013, p. 44). 
REVISTA X, Curitiba, volume 13,n.1,p. 116-140, 2018.

Dossiê Especial: Português como Língua Adicional em contextos de minorias:

(co)construindo sentidos a partir das margens

BIZON \& DINIZ (Orgs.)

Retomando o recorte da entrevista com a professora Marie, observamos que, embora demonstre interesse em organizar atividades como "fazer um teatrinho" ou "montar um coral", por considerá-las relevantes para o contexto de ensino e aprendizagem em que atua, considera que tais práticas não são muito valorizadas dentro da instituição - que, em seu discurso, é metonimicamente representada pelo "relatório anual". Provavelmente por não serem valorizados nesse relatório anual, é que, no próprio discurso de Marie, esse tipo de iniciativas, assim como o PPM, sejam concebidos como "nada acadêmicos", como destaca a professora. Marie acaba, assim, por reproduzir esse discurso que, na esteira do processo de capitalismo acadêmico, naturaliza um certo sentido para "acadêmico", do qual estão excluídas, entre outras, atividades de natureza artística.

Em minha própria experiência, também cheguei a uma conclusão parecida à da professora Marie quando, em minha seleção para o mestrado, tive de preencher uma tabela que pontuaria minha produção acadêmica para a etapa classificatória do processo. Foi no momento de preencher essas tabelas que me dei conta de que estágios docentes realizados no centro de extensão daquela mesma faculdade, assim como o tempo de experiência como professora do Curso de PLA para Candidatos ao PEC-G e a participação em demais projetos realizados durante meu período de graduação não valeriam pontos para meu ingresso no mestrado. Aqueles projetos só passariam a ter visibilidade na academia quando minha experiência docente desenvolvida neles se transformasse em artigos publicados em periódicos, de preferência aqueles que figurassem entre os periódicos Qualis mais bem-conceituados, que me renderiam pontos nas tabelas. Apresenta-se, assim, um indício de desvalorização da docência dentro dos próprios cursos de formação de professores.

Configura-se, dessa forma, um círculo vicioso como parte do funcionamento do capitalismo acadêmico, descrito por Slaughter \& Leslie (2001), Krawczyk (2008) e Bizon (2013): é acadêmico o que, do Currículo Lattes - ou de documentos semelhantes, como o relatório citado pela professora Marie, ou outros produzidos para CAPES, CNPq e outras agências de fomento -, pontua para o docente/pesquisador. Essa pontuação também gerará pontos para que as universidades subam nos grandes rankings 
REVISTA X, Curitiba, volume 13,n.1,p.116-140, 2018.

Dossiê Especial: Português como Língua Adicional em contextos de minorias:

(co)construindo sentidos a partir das margens

BIZON \& DINIZ (Orgs.)

acadêmicos internacionais para conseguirem mais investimentos para pesquisas que, por conseguinte, buscarão por atender aos critérios desses grandes rankings. Isso pode resultar num menor interesse de professores e estudantes em projetos como o PPM ou outras iniciativas, como as descritas pela professora Marie, e, consequentemente, numa desvalorização desse tipo de iniciativas e projetos dentro das universidades.

Ademais, é relevante ressaltar que as reflexões trazidas nesta subseção advêm, exatamente, das inquietações que emergiram em meu fazer como professora e pesquisadora diante do PPM. Ou seja: o projeto, que pode não ter sido visto por todos como "acadêmico" por não "valer pontos" segundo certos parâmetros adotados pela universidade, foi justamente o que contribuiu para o meu interesse de pesquisa, advindo das inquietações por ele geradas. Esse interesse resultou em minha pesquisa de mestrado, minha dissertação e este artigo, assim como minha participação em diferentes congressos acadêmicos, atividades consideradas importantes para o contexto acadêmico. E estas foram apenas algumas das contribuições do PPM, que, ademais, teve impactos importantes em minha própria formação, assim como na formação das outras professoras (MIRANDA, 2016) e no processo de aprendizagem dos estudantes, como veremos mais claramente na próxima seção. Assim, cabe-nos refletir sobre o que (não) tem sido considerado como experiência acadêmica por parte dos parâmetros de nossos programas de graduação e outras instituições que determinam tais parâmetros e critérios.

Na próxima seção, apresento algumas discussões advindas do PPM a partir da análise de algumas das entrevistas realizadas com estudantes do PEC-G participantes da pesquisa e do projeto.

\section{O projeto Pelo Mundo por meio das vozes de alguns/algumas dos/das estudantes envolvidos/envolvidas}

Nesta subseção do artigo, trago as vozes dos estudantes para compreender, a partir de sua perspectiva, o que foi o PPM, focalizado em nossa pesquisa. Por questões 
REVISTA X, Curitiba, volume 13,n.1,p.116-140, 2018.

Dossiê Especial: Português como Língua Adicional em contextos de minorias:

(co)construindo sentidos a partir das margens

BIZON \& DINIZ (Orgs.)

de espaço neste artigo, seleciono apenas algumas das discussões propostas em minha dissertação de mestrado.

Como expliquei anteriormente, as entrevistas foram realizadas com cinco estudantes da edição de 2015 do Curso de PLA para Candidatos ao PEC-G, a saber: Upendo, uma estudante do Quênia; Paulina, da Namíbia; Sona Victor, um estudante do Gabão; Lempira, um estudante de Honduras; e, finalmente, Sandy, uma estudante da República Democrática do Congo que, na verdade, se preparava para ingressar no Programa de Estudantes-Convênio de Pós-Graduação (PEC-PG).

Um primeiro aspecto em nossa análise de registros que nos pareceu bastante significativo foi a visibilidade alcançada pelos estudantes do Curso de PLA para Candidatos ao PEC-G depois da apresentação da peça de teatro, que, aparentemente, contribuiu para a sua integração na comunidade acadêmica na qual estavam inseridos naquele primeiro ano. $\mathrm{O}$ recorte a seguir, da entrevista com Paulina, pode ser esclarecedor nesse sentido.

\section{Recorte 3 - Trecho da entrevista à estudante Paulina}

Paulina: Um poema, e... quando eu falei em frente de todo mundo eu pensei... “então não tem... Ah... Eu não... eu posso... ficar mais fechado, porque as pessoas me aceitam. Então isso me fez tipo "Ah! Hello, Brasil”. (risos)

PP: Cheguei. (risos)

Paulina: Cheguei, agora cheguei. (risos)

(Entrevista realizada no segundo semestre de 2016. Grifos adicionados.)

Nesse trecho da entrevista, Paulina ressalta o que significou a apresentação da peça Pelo Mundo em sua experiência. Segundo ela, depois de recitar o poema - de sua própria autoria, escrito em português, em inglês e em africâner, algumas das línguas faladas por ela - em frente "de todo mundo", Paulina sentiu que realmente havia chegado ao Brasil: "Cheguei, agora cheguei". A apresentação da peça diante da comunidade à qual buscava se integrar foi, para a estudante, mais que uma atividade acadêmica, de prática do português ou preparatória para o exame Celpe-Bras. Para ela, 
REVISTA X, Curitiba, volume 13,n.1,p.116-140, 2018.

Dossiê Especial: Português como Língua Adicional em contextos de minorias:

(co)construindo sentidos a partir das margens

BIZON \& DINIZ (Orgs.)

apresentar a peça e recitar seu poema diante daquelas pessoas representou um deslocamento em seu processo de inserção na comunidade à qual buscava se integrar: de não aceita para aceita; de ficar fechada para abrir-se àquela experiência; de sentir que realmente, agora, havia, de fato, chegado ao Brasil.

Em outro momento da entrevista, perguntei aos estudantes sobre sua motivação para participar do PPM. Ressalto o estranhamento do estudante Sona Victor quanto ao modo como seu país e continente eram representados pelos brasileiros nas entrevistas realizadas durante o PPM, o que também foi observado no discurso de outros estudantes do Curso de PLA para Candidatos ao PEC-G.

\section{Recorte 4 - Sona Victor}

Sona Victor: Então, eu, pessoalmente, eu decidi. Falei "bom, vou fazer". Vou fazer por quê? Por que eu acho que eu preciso mostrar pras pessoas o... outro lado da África. O que é a África mesmo, o que é o Gabão, que é meu país. Então eu acho que precisava mesmo. Porque eu tô aqui no Brasil, todo envolvido nessa cultura, então preciso também mostrar pras pessoas... pros brasileiros minha... minha cultura ou a cultura africana. [...] Mostrar minha cultura e mostrar, também, apresentar um pouco... o... tipo assim, tirar essa dúvida da cabeça das pessoas o que é a África mesmo. Sobretudo isso. Porque, quando acabei de chegar aqui no Brasil. Nossa! O que tava entendendo da África, véi... Tipo assim... tava horrivel sabe? Eu tava pensando "nossa, isso é falta de conhecimento ou... isso... eles querem falar isso?". Mas... o que eu percebi, eu percebi que que tava falta de conhecimento, né? Então... a gente precisava mostrar isso. Demonstrar isso... O que é a África pras pessoas. Acho que... pelo menos a gente conseguiu, né?

(Entrevista realizada no segundo semestre de 2016. Grifos adicionados.)

Observamos que também Sona Victor havia chegado à conclusão, durante o desenvolvimento das atividades de entrevistas que também fizeram parte do PPM, de que o modo como ele concebia a África era muito diferente das visões encontradas por ele no Brasil. Sona Victor parece um tanto perplexo quanto a essa diferença: "Porque quando acabei de chegar aqui no Brasil. Nossa... O que estava entendendo da África. Tipo assim, estava horrível sabe?”. E, adiante, o estudante demonstra que, a princípio, não entendia o que fazia com que as pessoas dissessem aquele tipo de coisas sobre o continente africano: "Eu estava pensando 'nossa, isso é falta de conhecimento ou querem falar isso?" 
REVISTA X, Curitiba, volume 13,n.1,p.116-140, 2018.

Dossiê Especial: Português como Língua Adicional em contextos de minorias:

(co)construindo sentidos a partir das margens

BIZON \& DINIZ (Orgs.)

Analisando esses recortes a partir do LC, retomamos o que assinala Mattos (2014):

[o letramento crítico] constitui-se numa prática sócio-historicamente situada de construção de significado. De acordo com as autoras [FESTINO; MATTOS; MIZAN, 2008], esse processo implica a utilização de diferentes formas de produção, comunicação e recepção de signos linguísticos e visuais que existem em qualquer comunidade, ou seja, letramento crítico significa que o que está sendo lido, visto ou ouvido foi produzido de acordo com os valores e normas do contexto sócio-histórico da comunidade à qual o autor pertence. Além disso, o leitor, ouvinte ou espectador também está inserido em um contexto sócio-histórico e cultural que define a forma como o sentido é construído. $O$ ato de leitura torna-se crítico no momento em que a "diferença" é percebida e estabelecida entre o autor e o leitor que constroem significados de acordo com os valores de seus próprios contextos e, assim, tornam-se críticos não só do contexto do Outro, mas também de seu próprio contexto de produção. O objetivo final do letramento crítico é, assim, desafiar as relações de poder existentes e provocar mudança social. (MATTOS, 2014, p. 174. Grifos adicionados.)

Considerando o discurso de Sona Victor sob essa perspectiva, observamos que ele se encontrou com a "diferença" entre o que ele mesmo pensava sobre o continente africano e as concepções daqueles a quem conheceu, seja por meio das atividades do PPM (como as entrevistas pelos corredores da universidade e num mercado popular da cidade), seja em seu dia a dia no Brasil. Sua surpresa diante dessa diferença revelou, de alguma forma, as diversas construções de significado sobre o continente africano. Assim, o estudante teve, por meio do trabalho ancorado no LC, a oportunidade de refletir sobre seus próprios valores e normas, assim como aqueles dos contextos sóciohistóricos e culturais em que estava se inserindo, dentro e fora da universidade, em sua experiência de vida e estudos no Brasil. Desse encontro com a diferença, adveio o desejo por mudança, por transformação, tanto por parte das professoras como por parte dos estudantes (MIRANDA, 2016). A partir das discussões e debates mediados pelas professoras nas aulas, engajadas com o LC para o curso ministrado e com uma formação cidadã dos estudantes, surgiu o desejo por mudança, que se manifestou em diferentes iniciativas, culminando no PPM.

Como salienta Mattos (2014), em concordância com Wenger (1998), 
REVISTA X, Curitiba, volume 13,n.1,p. 116-140, 2018.

Dossiê Especial: Português como Língua Adicional em contextos de minorias:

(co)construindo sentidos a partir das margens

BIZON \& DINIZ (Orgs.)

[...] a educação não é apenas formadora, mas é também transformadora. A educação para a cidadania também focaliza a transformação. No entanto, enquanto a educação visa à transformação do indivíduo, a educação para a cidadania visa à transformação de grupos sociais através da participação ativa dos indivíduos (MATTOS, 2014, p. 173).

Nesse "caos produtivo instaurado pela visão de que o mundo é plural, múltiplo e móvel” (JORDÃO, 2014, p. 201), professoras e estudantes puderam se perceber tanto como narradores e narrados, narrando a si mesmos e aos outros, tendo, a partir dessa percepção, a possibilidade de transformar a realidade enquanto agentes no mundo (ibidem).

Contudo, comprometidos com a perspectiva da Linguística Aplicada Indisciplinar, "continuamente autorreflexiva" (MOITA LOPES, 2006, p. 15), ainda que acreditemos na possibilidade de agência dos indivíduos no mundo e na transformação social a partir de uma formação cidadã de nossos estudantes e, justamente por isso, tenhamos escolhido a perspectiva do LC para o desenvolvimento de nosso curso e do PPM, não podemos negligenciar o fato de que, como destacou Maher (2007), apenas o fortalecimento político ou o empoderamento de nossos estudantes não basta para uma transformação social, o alcance de seus direitos, a visibilização e transformação de sua situação. Como já mencionamos em nosso referencial teórico, na visão da autora, são necessários três cursos de ação: “(1) de sua politização; (2) do estabelecimento de legislações a eles favoráveis; e (3) da educação do seu entorno para o respeito à diferença" (MAHER, 2007, p. 257). Ainda que sejamos tentados a classificar o PPM como um projeto que trouxe transformação para os estudantes e para o contexto em que estão inseridos, nosso compromisso com essa perspectiva crítica e autorreflexiva de uma Linguística Aplicada Indisciplinar e com o LC nos alerta para o fato de que ainda há muito para se discutir, problematizar, debater.

Mesmo que, como professora e pesquisadora, tenha observado grandes mudanças nos discursos dos estudantes desde o início do curso até a data em que os entrevistei, nos recortes apresentados nesta pesquisa é possível observar, ainda, falas como "A gente apresentou a cultura africana, diante de..." ou "...tirar essa dúvida da cabeça das pessoas. O que é a África mesmo", para citar alguns trechos, em que se 
REVISTA X, Curitiba, volume 13,n.1,p.116-140, 2018.

Dossiê Especial: Português como Língua Adicional em contextos de minorias:

(co)construindo sentidos a partir das margens

BIZON \& DINIZ (Orgs.)

nota uma concepção de cultura como solidificada e homogênea e em que se ignora a visão de que "realidade e observador são inseparáveis: só se tem conhecimento do real mediante nosso olhar, nossa leitura dele" (JORDÃO, 2014, p. 198). Por outro lado, em outros momentos, os estudantes apresentam uma reflexão que demonstra não só um amadurecimento crítico quanto à forma como são narrados pelos outros, mas também quanto à forma como narram os outros e a si mesmos.

Tendo apresentado minhas análises dos registros gerados nesta pesquisa, na próxima seção, apresento algumas considerações finais acerca deste trabalho.

\section{CONSIDERAÇÕES FINAIS}

No presente artigo, apresentei alguns dos resultados de minha pesquisa de mestrado, buscando analisar algumas das contribuições do PPM para a configuração de uma política linguística pluricêntrica capaz de cooperar para a visibilização do PEC-G no processo de internacionalização das IES brasileiras, assim como para uma formação crítica dos estudantes do Curso de PLA para Candidatos ao PEC-G e para a educação do entorno (MAHER, 2007).

Como observamos no exposto até aqui, o PPM favoreceu considerações sobre meu fazer como professora e pesquisadora quando me deparei com os diferentes desafios e inquietações enfrentados pelos estudantes do Curso de PLA para Candidatos ao PEC-G que dele participaram, assim como com as questões que surgiram nas entrevistas realizadas durante a geração de registros para esta pesquisa, que teve como foco o desenvolvimento do PPM. Ao assistir à peça de teatro, uma das atividades desenvolvidas no interior do projeto focalizado, a professora Marie pôde refletir sobre seu fazer como professora dentro da universidade federal onde trabalha e eu, como pesquisadora, pude analisar esse processo à luz dos estudos sobre o processo de capitalismo acadêmico. Ademais, pude analisar minha própria experiência como estudante de pós-graduação quanto aos critérios utilizados para avaliação de nosso desempenho como pesquisadores no interior do programa de pós-graduação ao qual me vinculo. 
REVISTA X, Curitiba, volume 13,n.1,p. 116-140, 2018.

Dossiê Especial: Português como Língua Adicional em contextos de minorias:

(co)construindo sentidos a partir das margens

BIZON \& DINIZ (Orgs.)

Por outro lado, o PPM também pareceu contribuir para a formação cidadã e crítica (MATTOS; VALÉRIO, 2010) dos estudantes do Curso de PLA para Candidatos ao PEC-G, cujo processo de ensino-aprendizagem de PLA se deu em um curso fundamentado nos pressupostos do LC e da Linguística Aplicada Indisciplinar. Como apontaram os recortes das entrevistas de Paulina e Sona Victor, ao participarem do projeto, os estudantes tiveram a oportunidade de tratar publicamente de algumas das inquietações e questões que perpassam sua vida no Brasil como estudantes conveniados ao PEC-G.

Em minha perspectiva, acredito que o trabalho desenvolvido pelas professoras, os estudantes e o coordenador do curso buscou por uma política linguística que visibilizasse as vozes dos alunos, o que culminou na elaboração e desenvolvimento do PPM. Por meio desse projeto, configurou-se uma política linguística voltada para um processo de ensino-aprendizagem direcionado a uma perspectiva intercultural ${ }^{16} \mathrm{e}$ preocupado com o LC. Essas iniciativas visaram a contribuir para a formação cidadã e crítica dos estudantes, de modo que estes pudessem, cada vez mais, se posicionar diante das formas como estavam sendo narrados pela sociedade à qual estavam buscando se integrar e, ao mesmo tempo, refletir sobre o modo como narravam a si mesmos e aos seus colegas de sala.

O desenvolvimento do curso de que fez parte o PPM, não só visibilizou os estudantes na Faculdade de Letras onde estudavam PLA antes de prestar o exame Celpe-Bras, mas também trouxe à tona suas inquietações e visibilizou suas vozes tanto no contexto acadêmico (nas duas primeiras apresentações, realizadas dentro da Faculdade de Letras daquela universidade) quanto fora dela (na escola municipal pela qual os estudantes foram convidados a apresentar a peça). Assim, ainda que não tenha a ilusão de que o PPM tenha sido "perfeito" ou que seja um projeto modelo para outras instituições - pois, como venho defendendo até aqui, os seres humanos são heterogêneos, assim como são heterogêneos os diferentes cursos para candidatos ao PEC-G desenvolvidos em diferentes IES ao redor do Brasil -, observamos, nas análises

\footnotetext{
${ }^{16}$ Em consonância com Maher (2007), mobilizo o conceito de interculturalidade como recurso teórico importante para destotalizar o outro e aceitar seu caráter mutável. Como salienta a autora, nessa perspectiva, busca-se a convivência com a diferença da forma mais respeitosa e informada possível.
} 
REVISTA X, Curitiba, volume 13,n.1,p. 116-140, 2018.

Dossiê Especial: Português como Língua Adicional em contextos de minorias:

(co)construindo sentidos a partir das margens

BIZON \& DINIZ (Orgs.)

aqui expostas, sua contribuição para a configuração de uma política linguística coerente com as diretrizes do convênio, alicerçado, sobretudo, no objetivo de uma cooperação internacional, de acordo com o trecho do decreto apresentado anteriormente.

Finalmente, espero que as discussões apresentadas neste artigo contribuam para gerar outras inquietações em professores de cursos de PLA para diferentes grupos e com diferentes especificidades, a fim de que o diálogo continue e, mais que encontrar respostas, permita levantar outras perguntas para seguirmos em uma jornada autorreflexiva de nosso fazer como professoras-pesquisadoras e professorespesquisadores.

\section{REFERÊNCIAS}

ALFORD, J. Learning language and critical literacy: adolescent ESL students. Journal of Adolescent \& Adult Literacy, v. 45, n. 3, p. 238-242, 2001.

BIZON, A. C. C. Narrando o exame Celpe-Bras e o convênio PEC-G: a construção de territorialidades em tempos de internacionalização. 2013. 445f. Tese (Doutorado). Universidade Estadual de Campinas, Campinas.

BRASIL. Ministério da Educação. Manual do Programa de Estudantes-Convênio de Graduação PEC-G. Governo Federal, 2000.

CALVET, L.-J. As políticas linguísticas. São Paulo: Parábola/IPOL, 2007.

CAVALCANTI, M. C. Educação linguística na formação de professores de línguas: intercompreensão e práticas translíngues. In: MOITA LOPES, L.P. (org.). Linguística Aplicada na Modernidade Recente - Festschrift para Antonieta Celani. São Paulo: Parábola/Cultura Inglesa, p. 211-226, 2013.

DINIZ, L. R. A. Política linguística do Estado brasileiro na contemporaneidade: a institucionalização de mecanismos de promoção da língua nacional no exterior. 2012. 396f. Tese (Doutorado em Linguística). Instituto de Estudos da Linguagem, Universidade Estadual de Campinas, Campinas.

DINIZ, L. R. A.; BIZON, A. C. C. Discursos sobre a relação Brasil/África "lusófona" em políticas linguísticas e de cooperação educacional. Línguas e Instrumentos Linguísticos, v. 36, p. 125-165, 2015.

FERRAZ, D. M. Letramento visual: as imagens e as aulas de inglês. In: TAKAKI, N. H.; MACIEL, R. F. (Orgs.). Letramentos em terra de Paulo Freire. Campinas,SP: Pontes Editores, p.255-270, 2014. 
REVISTA X, Curitiba, volume 13,n.1,p. 116-140, 2018.

Dossiê Especial: Português como Língua Adicional em contextos de minorias:

(co)construindo sentidos a partir das margens

BIZON \& DINIZ (Orgs.)

FESTINO, C. G.; MATTOS, A. M. A.; MIZAN, S. Becoming critical: teaching and learning through critical literacy. In: CONGRESSO LATINO-AMERICANO DE FORMAÇÃO DE PROFESSORES DE LÍNGUAS, 2., 2008, Rio de Janeiro. Caderno de Resumos... Rio de Janeiro, RJ: Pontifícia Universidade Católica do Rio de Janeiro, p. 111-113, 2008.

FRANCO, S. B. A língua age: política externa brasileira e a difusão da língua portuguesa. 2015. 185f. Dissertação (Mestrado). Universidade Federal de Santa Catarina, Florianópolis.

FREIRE, P. Pedagogia da autonomia: saberes necessários à prática da autonomia. São Paulo: Paz e Terra, 1998.

GIKANDI, S. Globalization and the Claims of Postcoloniality. In: DESAI, G.; NAIR, S. (Eds.) Postcolonialism: an anthology of cultural theory and criticism. New Brunswick; New Jersey: Rutgers University Press, p. 608-634, 2005.

JORDÃO, C. M. Uma breve história da leitura no século xx, ou de como se podem calar as nativas. Revista de Letras, v. 5, 2002. Disponível em: <http://www.dacex.ct.utfpr.edu.br/clarisse5.htm>. Acesso em: 20 ago. 2007.

Birds of different feathers: algumas diferenças entre letramento crítico, pedagogia crítica e abordagem comunicativa. In: TAKAKI, N. H.; MACIEL, R. F. (Orgs.). Letramentos em terra de Paulo Freire. Campinas, SP: Pontes editores, p. 195-207, 2014.

KRAWCZYK, N. R. As políticas de internacionalização das universidades no Brasil: o caso da regionalização no Mercosul. Jornal de Políticas Educacionais, n. 4, p. 41-52, jul./dez 2008.

LUKE, A. Two takes on the critical. In: NORTON, B.; TOOHEY, K. (Eds.). Critical Pedagogies and Language Learning. Cambridge: Cambridge University Press, p. 110, 2003.

MAHER, T. M. A Educação do Entorno para a Interculturalidade e o Plurilinguismo. In: KLEIMAN, A. B.; Cavalcanti, M. C. (orgs.) Linguística Aplicada: faces e interfaces. Campinas, SP: Mercado de Letras, p. 255-270, 2007.

Em busca de conforto linguístico e metodológico no Acre indígena. Trabalhos em Linguística Aplicada, Campinas, 47, 2, p. 409-428, jul./dez. 2008.

MATTOS, A. M. A. e VALÉRIO, K. M. Letramento crítico e ensino comunicativo: lacunas e intersecções. RBLA, v.10, n.1, p. 135-158, 2010. 
REVISTA X, Curitiba, volume 13,n.1,p. 116-140, 2018.

Dossiê Especial: Português como Língua Adicional em contextos de minorias:

(co)construindo sentidos a partir das margens

BIZON \& DINIZ (Orgs.)

MATTOS, A. M. A. Construindo Cidadania nas Aulas de Inglês: uma proposta para o letramento crítico. In: TAKAKI, N.H. ; MACIEL, R.F. (Org.). Letramentos em Terra de Paulo Freire. Campinas, SP: Pontes, p. 171-191, 2014.

McCARTY, T. L. Dangerous difference: a critical-historical analysis of language education policies in the United States. In: TOLLEFSON, J. W.; TSUI, A. B. M. Medium of instruction policies: which agenda? Whose agenda? Mahwah, NJ: Lawrence Erlbaum Associates, p. 71-98, 2004.

MIRANDA, Y. Projeto "Pelo Mundo": a configuração de uma política linguística em um curso de português como língua adicional para candidatos ao Programa de Estudantes - Convênio de Graduação. 2016. 178f. Dissertação (Mestrado). Universidade Federal de Minas Gerais, Belo Horizonte.

MOITA LOPES, L. P. Por uma linguística aplicada indisciplinar. São Paulo: Parábola, 2006.

Introdução. Uma linguística aplicada mestiça e ideológica: interrogando o campo como linguista aplicado. In: MOITA LOPES, L. P. Por uma Linguística Aplicada Indisciplinar. São Paulo: Parábola, p. 13-44, 2006.

MONTE MÓR, W. Crítica e letramentos críticos: reflexões preliminares. In: MACIEL, R. F.; ROCHA, C. H. Língua Estrangeira e Formação Cidadã: por entre discursos e práticas. Campinas,SP: Pontes Editores, 2013.

PENNYCOOK, A. Uma linguística aplicada transgressiva. In: MOITA LOPES, L. P. Por uma Linguística Aplicada Indisciplinar. São Paulo: Parábola, p. 67-84, 2006.

SLAUGHTER, S; LESLIE, L. Expanding and elaborating the concept of Academic Capitalism. Organization, Sage, v. 8, n. 2, p. 154-161, 2001.

WENGER, E. Communities of practice: Learning, meaning and identity. Cambridge: Cambridge University Press, 1998. 